\title{
Pimentas do gênero Capsicum cultivadas em Roraima, Amazônia brasileira. II. Hábitos e formas de uso
}

Herundino Ribeiro do NASCIMENTO FILHO ${ }^{1}$, Reinaldo Imbrozio BARBOSA², Francisco Joaci de Freitas LUZ $^{3}$

RESUMO

O objetivo do trabalho foi o de relacionar e discutir os hábitos e as formas de uso mais comuns das pimentas do gênero Capsicum cultivadas em Roraima, e utilizadas pelos povos indígenas e comunidades migrantes de outras regiōes do país.

PaLAVRaS-ChaVE: Pimentas, Capsicum, Índios, Migrantes, Roraima.

\section{Peppers of the genus Capiscum cultivated in Roraima, Brazilian Amazonia. II. Habits and forms of use}

ABSTRACT

The objective of this study was relate and discuss both the habit and the most common forms of using Capsicum peppers cultivated in the state of Roraima and utilized by indigenous people and colonist communities from the other regions of the country.

KEYWORDS: Peppers, Capsicum, Indians, Colonists, Roraima.

1 Conselho Indígena de Roraima (CIR), Av. Sebastião Diniz 2630, Bairro São Vicente, 69300-000 Boa Vista - Roraima, Tel/fax: (95) 3224 5761, e-mail: heribeiro@technet.com.br

2 INPA. e-mail: reinaldo@inpa.gov.br

3 e-mail: joaci@cpafrr.embrapa.br 


\section{INTRODUÇÃO}

Este trabalho é parte integrante de um levantamento das espécies e variedades de pimentas (Capsicum spp.) utilizadas no estado de Roraima que foi realizado entre 2000 e 2001 (Barbosa et al., 2002). A idéia geral foi a de verificar quais as espécies de pimentas domesticadas do gênero Capsicum spp., que são tradicionalmente empregadas pelas diferentes vertentes culturais de Roraima (indígenas e não-indígenas), e que vem sofrendo alterações nos últimos 20-30 anos devido às fortes correntes migratórias ocorridas nesta região da Amazônia. O objetivo desta vertente do estudo foi o de coletar informações sobre os hábitos e as formas de uso (alimentar, medicinal, etc.) que a "pimenta" assume tanto em populaçóes indígenas quanto em não-indígenas de Roraima. Este é um passo fundamental para articular, registrar e diferenciar processos de manutenção da diversidade cultural local, que podem implicar em alternativas ao desenvolvimento sócio-ambiental regional.

Para transcorrer sobre o tema em tela, foi realizado um levantamento bibliográfico básico para entender como as pimentas do gênero Capsicum foram interpretadas e relatadas ao longo dos diferentes períodos históricos, até chegar ao que hoje é geopoliticamente definido como o estado de Roraima. Dentro do escopo do trabalho de levantamento das espécies locais, foram aproveitados os relatos e depoimentos orais das pessoas mais idosas e das lideranças locais como pajés, professores e "tuxauas" presentes nas aldeias indígenas. Nas comunidades não-indígenas, foram aproveitados os relatos dos proprietários dos cultivos rurais e urbanos, além de comerciantes das feiras livres das sedes municipais de Boa Vista (capital do Estado), Caracaraí, Alto Alegre, Rorainópolis, Pacaraima e Uiramutã, além das vilas do Socó, São Raimundo, Equador, Jundiá e Mutum. Todo o trabalho transcorreu entre os anos de 2000 e 2001. Parte do relato histórico deste manuscrito é derivado do livro que foi editado pelo Instituto Nacional de Pesquisas da Amazônia (INPA), em parceria com a Editora da Universidade do Amazonas (EDUA), denominado "Pimentas de Roraima (Catálogo de Referência)" (Barbosa et al., 2006).

\section{ALINHAMENTO HISTÓRICO}

\section{NOTÍCIAS DO BRASIL}

$\mathrm{O}$ gênero Capsicum, incontestavelmente exclusivo das Américas, se expandiu com grande velocidade por outras partes do mundo a partir do século XVI, quando o relacionamento entre as populações européias e os povos indígenas foi intensificado (Heiser, 1976; Casali \& Couto, 1984; Garcia, 1991). Vários registros arqueológicos indicam que o gênero Capsicum já vinha sendo consumido há pelo menos 8.6005.600 a.C. nas regiōes andinas do Peru, e há 6.500-5.500 a.C. no México (Nuez et al., 1998). Juntamente com os gêneros Phaseolus (feijāo) e Cucurbita (abóboras), as pimentas faziam parte das primeiras plantas a serem domesticadas nas Américas.

Para a época do Brasil Colônia, existem alguns relatos sobre o uso de pimentas pelas populaçôes indígenas contatadas nas regióes do litoral brasileiro e na Mata Atlântica. Segundo Reifschneider (2000:14-15), o principal deles deve ser atribuído ao náufrago alemão Hans Staden que se estabeleceu entre os Tupinambá no período de 1547-1555 (Staden, 1974). No capítulo 38 ("Como crescem o algodão e a pimenta brasileira ...") de uma das narrativas de seu livro ("Relatório sobre algumas árvores daquela terra"), Staden apresenta a descrição e a forma de conservação de "... duas qualidades de pimenta ..." utilizadas pelas populaçōes indígenas da época.

$\mathrm{Na}$ Amazônia, com a intensificação das expedições exploratórias a partir de 1538 com Diogo Nunes (Papavero et al., 2000), as atençōes se voltaram para as potencialidades regionais como o cacau, o fumo, a cana-de-açúcar e a salsaparrilha, como atestado por Acunã (1641) quando da viagem de Pedro Teixeira entre 1637-39 pelo rio Amazonas. Entretanto, algumas citaçóes desta época já apontavam a grande importância das pimentas na alimentação das populações amazônicas. Por exemplo, Sylveira (1624), em sua crônica sobre a então região do Maranhão, indicou a existência de "Pimenta em grande quantidade ..." quando do capítulo das drogas locais. Day (1632), comentado em Lorimer (1989), também havia citado a presença de “... Ginnipeper ..." (pimenta da Guiné) na região do estuário do Amazonas (Cabo do Norte). No Brasil Império, Humboldt (1814), citado por Heiser \& Smith (1953), quando de sua passagem pela América do Sul, comentou que as pimentas seriam "... tão indispensavelmente necessárias aos nativos quanto o sal para os brancos".

\section{VALE DO RIO BRANCO}

Em Roraima, situado no extremo norte da Amazônia, não são muitas as referências de uso de pimentas pelas comunidades indígenas no passado ou pela população migrante recente, sendo latente a utilização deste vegetal em diferentes situaçōes e extratos sociais. As primeiras escavaçôes em sítios arqueológicos de Roraima, realizadas principalmente nas áreas de savana do nordeste do Estado, não determinaram a utilização de Capsicum na alimentação dos primeiros habitantes locais, que estão situados na região há aproximadamente 3000-4000 anos antes do presente (AP), podendo ser recuados para até 7000 anos AP (MentzRibeiro, 1997). Isto talvez tenha sido devido ao início tardio da domesticação de algumas espécies regionais ou a um investimento maior nas atividades de coleta e caça. Além disto, o clima quente e úmido da região pouco favorece a preservação de vestígios alimentares em sítios amazônicos de baixa altitude. 
Estes primeiros achados não eliminam o uso de pimentas na alimentação dos primeiros habitantes locais.

Nos antigos relatos de Sampaio (1774-75), Ferreira (1786a,b; 1787), D’Almada (1787) e Schomburgk (1840), onde há discussões sobre os recursos naturais da região do Vale do Rio Branco (hoje Roraima), não consta como potencialidade regional, a presença deste tipo de vegetal entre as culturas indígenas da época. Apenas em Ule (1913), de quando sua viagem de pesquisa ao rio Branco em 1908, apareceria uma citação de que os índios locais não só plantam espécies de Capsicum, como também comem um tipo de purê “... fortemente apimentado ...". Em seguida, na extensa investigação etnológica de Koch-Grünberg (1979-82), que percorreu toda a região dominada pelo Monte Roraima e Serra Parima entre os anos de 1911-13, foi possível encontrar vestígios do uso de plantas do gênero Capsicum entre as populações locais. Koch-Grünberg fez várias citações (Tomo I, pags. 43 ; 257; 275; 307) sobre o uso do “... caldo de pimenta ...” (provavelmente damorida ), da “... salsa de pimenta ..." (um tipo de molho) e da "... pimenta fresca ..." (frutos frescos adicionados diretamente à alimentação); todos muito utilizados entre os Macuxi e Wapichana e, por ele mesmo ao longo de suas caminhadas pelas áreas de mata e savanas regionais, o que demonstra o uso generalizado da pimenta à época.

Pereira (1980) apresenta uma imagem de vários indígenas saboreando a “... tamorida ..." (damorida) como uma das formas de socialização realizada entre a etnia Ingarikó do alto rio Cotingo. Berg \& Silva (1988) realizaram um levantamento sobre a flora medicinal de Roraima em 1984, indicando que a pimenta malagueta ( $C$. frutescens L.) era utilizada no combate ao "pano branco" de pele. Investigações etnobotânicas de Azevedo Lima (1990) e Milliken et al. (1992) indicaram o plantio de pimentas do gênero Capsicum nas roças Waimiri-Atroari, situadas no extremo sul de Roraima, para aproveitamento alimentar. Outro levantamento feito por Milliken \& Albert (1997) e Milliken et al. (1999) também relatou a utilização de $C$. frutescens como planta de uso medicinal pela etnia Yanomami, principalmente infecções respiratórias e oftalmia. A mesma espécie também era usada no passado para tratamento da malária por algumas comunidades Wapichana do leste de Roraima (Milliken, 1997).

Estes relatos não esgotam o vasto uso destes frutos por todas as comunidades urbanas e rurais atualmente residentes em Roraima. As cores, as formas e os sabores são de grande variedade, e vem sendo construídos e adaptados a partir de uma enorme movimentação genética entre as diferentes correntes humanas deslocadas para Roraima nas últimas décadas.

\section{HÁBITOS E FORMAS DE USO}

Para transcorrer sobre as formas de uso das pimentas em Roraima, entende-se que seria conveniente dividir a discussão em dois seguimentos sociais distintos: (a) "indígenas", com histórico milenar de uso, e (b) "migrantes", com história recente, e que se distribuíram por diversas regiōes de Roraima, principalmente através dos projetos de colonização patrocinados pelo poder público a partir de meados dos anos 1970.

\section{OS INDÍGENAS}

Dos 180 acessos de pimentas (163 de espécies domesticadas) coletados em Roraima no período de maio/2000 a junho/2001, foram identificados 78 morfotipos que se diferenciavam pela forma, cor e ardência (Barbosa et al., 2002). Destes, 23 foram observados especificamente para etnias indígenas: Wapixana (10), Macuxi (9), Patamona (1), Yanomami (1) e Yekuana (1). Nestas comunidades, os morfotipos predominantes foram malagueta ( $C$. frutescens), murupi (C. chinense) e olhode-peixe (C. chinense). Devido ao esforço de coleta ter sido mais intenso entre as comunidades Macuxi e Wapichana, este resultado acaba refletindo uma situação muito simplificada dos morfotipos utilizados pelas etnias locais, observando-se principalmente aquelas que vivem nas regiões de vegetação aberta denominadas regionalmente por "lavrado" - savanas/ cerrados (ver Barbosa \& Miranda, 2005)

A coleta de pimentas nas etnias indígenas presentes no ecossistema de florestas foi muito reduzida devido a problemas de acessibilidade. Todavia, tanto as poucas coletas que obtivemos, quanto os relatos passados, nos dão conta do uso de pimentas nestas localidades como, por exemplo, nos trabalhos de Milliken (1997) entre os Yanomami do oeste de Roraima, e Meggers (1987) nos Waiwai, do sudeste.

Por ocasiāo das observaçóes nas aldeias do lavrado, foi constatado que, em sua maioria, existia a figura da "pimenteira". Este termo denomina uma ou mais senhoras (ou famílias) que se dedicam ao cultivo, manipulação e distribuição das pimentas na aldeia e/ou região. $\mathrm{Na}$ maior parte das vezes, estas senhoras também se responsabilizam pelo fabrico e comercialização de molhos e pimentas desidratadas/ moídas (jiquitaia). Neste caso, entenda-se comercialização como o ato de venda ou troca dentro e fora da aldeia. Não é um papel definido somente pela comunidade, entretanto, estas senhoras (pimenteiras) acabam assumindo esta figura através da leitura que a comunidade faz de seu prazer pessoal no plantio e tratos hortícolas de seu jardim doméstico.

Do ponto de vista cultural, as pimentas podem assumir diferentes formas simbólicas refletidas diretamente em sua forma de uso. Por exemplo, para os Macuxi, situados no centro-norte e nordeste de Roraima, andar no mato com fome 
e sem pimenta é muito perigoso, pois isto pode levá-los a ser atacados pelos espíritos das matas.

$\mathrm{Na}$ Aldeia Maturuca, o professor da escola indígena local (Prof. Sobral André, índio Macuxi) nos informou que naquela localidade as pimentas são usadas para fazer molhos à base de tucupi (escorrido da macaxeira), além do caldo (damorida) e da jiquitaia. A jiquitaia é geralmente preparada primariamente pela secagem da pimenta ao sol ou torrada no forno ou na pedra. Em seguida ela é moída em pilão e, na formulação atual, é adicionada uma quantidade variável de sal, muito embora antes do contato com o "... branco..." este último ingrediente não existisse. "Também se usa pimentas para espantar os maus espiritos ou feitiços ... espiritos da natureza que nós acreditamos que fazem mal' (Prof. Sobral André, índio Macuxi).

Os benzedores (pajés) utilizam as pimentas para curar doenças que só eles possuem o poder de tirar. Os pajés Macuxi, quando "... atuados ..." (em transe), usam pimentas em seus ritos, mas não conseguem se lembrar de quais e nem de quanto usaram nas composições indicadas aos doentes quando despertam do transe.

Entre os Macuxi, ao se doar uma pimenta in-natura a uma pessoa, é costume nunca entregar diretamente na mão deste, pois isso pode provocar o rompimento da amizade no curto prazo. Para tanto, deixam-se as pimentas em um local onde a pessoa interessada possa ser avisada para que possa pegá-las. "Assim a amizade durará muito ...".

Entre os Wapichana, segundo Nádia Farage em um pronunciamento realizado na Universidade Federal de Roraima em março de 2002, as pimentas também são usadas pelos familiares dos indivíduos mortos por ataque do "Canaimê" (figura mística). Estes colocam os frutos sobre sua sepultura para que o mesmo não venha completar o serviço. Neste caso, o termo "completar o serviço" possui o significado de comer, através dos animais que lhe representam (tatu, tamanduá, etc), os restos do cadáver.

Além das pimentas domesticadas, os índios de Roraima também utilizam outras espécies (semi-domesticadas e silvestres). A mais interessante, e que nos chamou a atenção, foi o uso de uma pimenta silvestre que nasce naturalmente em serras ou pé-de-serra das regiões do centro-norte e nordeste de Roraima. Para os indígenas, estas pimentas são plantadas em suas roças pelo "Curupira" ou "Atai-taî". Por causa desta crença mística, esta pimenta recebe o nome simbólico de "Pimenta do Curupira" ou simplesmente "pimirö" (pimenta pequena, na língua Macuxi). Esta espécie silvestre é uma Capsicum chinense que posiciona Roraima como um dos centros de dispersão desta espécie nesta regiāo do extremo norte amazônico (ver Barbosa et al. 2002; 2006).

O uso simbólico e medicinal da pimenta pelos índios do lavrado (cerrado/savana) é também muito amplo. Assim como os Yanomami da floresta, os Macuxi, Wapichana e Taurepang do lavrado também usam a malagueta (C. frutescens) para curar oftalmia, febre e até malária. Usam-na como disciplinadora entre as crianças, quando estas desobedecem ou fazem malcriação. Para tanto, os pais introduzem um fruto de pimenta malagueta, com a ponta inferior quebrada, no ânus da criança mal-criada para que esta fique obediente e esperta (Tuxaua Antônio, Aldeia do Contão).

Segundo relatos de alguns indígenas Macuxi mais velhos, o ato de introduzir pimentas no ânus também servia para que os adolescentes masculinos se tornassem bravos guerreiros, apurando sua esperteza e corrida. Neste ritual eram usadas lâminas de pedras para se fazer cortes superficiais nos braços, pernas e costas dos adolescentes. Em seguida, uma pasta de macerado de folhas de "curawa" (Agave sp.), juntamente com frutos de pimentas malagueta, era passada sobre os cortes. Segundo os velhos indígenas, neste momento, os adolescentes corriam em volta da casa em grande velocidade e, depois, rumo ao curso d'água mais próximo para aliviar a dor. Esse era um dos ritos de passagem masculino mais usado pelos índios Macuxi do lavrado.

O comércio interétnico, antes da intensificação do contato, usava as pimentas desidratadas e moídas (jiquitaia) como forma de produto de barganha. Este fato foi sempre apontado como uma característica forte dos indígenas da regiāo das serras, que desciam até a região dos lavrados para realizar negócios, trazendo, entre outras coisas, a jiquitaia para trocar por produtos desta regiāo de baixa altitude de Roraima (José Adalberto, índio da Aldeia Enseada, ex-consultor da APIR Associação dos Povos Indígenas de Roraima).

\section{OS MIGRANTES}

O grande número de migrantes derivados de diversas regiōes do país que adentraram em Roraima, principalmente a partir do final dos anos 1970, também faz um extenso uso de pimentas. A maioria trouxe costumes de cultivo e de consumo de pimentas de suas regiōes de origem. Dentre esses, aqueles que são considerados como apreciadores de pimentas, acabam construindo seu canteiro caseiro para consumo próprio ou para amigos mais próximos. Entretanto, certos tipos de pimenta vem sendo cultivados comercialmente como uma das formas de sustento econômico desta população migrante. Diferente dos indígenas, as cultivares mais adotadas são popularmente conhecidas como pimenta-de-cheiro; três morfotipos de $C$. chinense que possuem mercado cativo tanto em Boa Vista (capital de Roraima) como em Manaus (capital do Amazonas). Neste último caso, o produto é adquirido diretamente de sítios hortifrutigranjeiros próximos de Boa Vista, além das frentes de colonização situadas tanto no oeste como ao sul de Roraima. Nos dois primeiros casos, o produto serve ao abastecimento da capital local. No último caso (sul de Roraima), o transporte da mercadoria é realizado pelos caminhoneiros que fazem o 
trajeto de Boa Vista para Manaus, no sentido de abastecer àquele grande centro comercial amazônico.

Em Boa Vista, os locais de grandes vendas são as feiras livres conhecidas por Produtor Rural, Passarão e Feirão do Garimpeiro. De lá o produto é vendido ao público em geral ou a atravessadores para revenda em pequenos comércios e supermercados. Quando a venda é destinada ao público em geral, ela é realizada geralmente na base do "litro", uma unidade de medida local que se refere ao volume de qualquer produto, vendido nas feiras livres, que possa caber em uma lata de óleo de $900 \mathrm{ml}$. Esta unidade também é usada para outros produtos das feiras.

A maioria das pimentas-de-cheiro é vendida in natura e, embora as pimentas picantes também possam ser assim comercializadas, há uma forte preferência para que estas últimas sejam vendidas na forma de molhos sob as mais diversas bases: tucupi, vinagre, soro-de-leite, água e sal, óleo, etc. Isto faz com que o produto agregue valor econômico. Quando as pimentas picantes são vendidas in natura, elas são acondicionadas em pequenos sacos de plástico que se diferenciam no preço de acordo com a variedade, a aparência e o peso. Em geral o valor do quilograma, oscilou entre cinco a vinte e cinco reais, por quilo de fruto fresco, entre os anos de 2001 e 2006.

A prática da desidratação e moagem de pimentas (jiquitaia) tradicionalmente é de domínio da cultura indígena. Entretanto, em alguns casos os colonos migrantes já trouxeram essa prática de sua região ou a adquiriram entre a população local. Por isso, este produto é facilmente encontrado nas feiras de Boa Vista. Outra forma de uso da pimenta entre os colonos é a venda de pequenos jarros com mudas de plantas ornamentais, com o nome popular de "pimenta-de-mesa". Em geral, são plantas da espécie semi-domesticada $C$. annuиm v. glabriusculum que, pelo seu porte e beleza são usadas na decoração ou como um talismã contra o mal-olhado. As flores desta variedade possuem, em geral, uma tonalidade que varia muito em torno da cor púrpura, atraindo pessoas interessadas na ornamentação de jardins ou mesas.

\section{OS PRODUTOS}

De acordo com as informaçôes coletadas em campo dentro da contextualização etnohistórica, foi montada uma tabela com as classes de produtos e formulações básicas, das diferentes formas de usos e seus respectivos agentes sociais, produtores e consumidores de pimentas em Roraima (Tabela 1).

\section{COMENTÁRIOS SOBRE OS PRODUTOS}

Arubé - Todos os ingredientes precisam ser levados ao fogo até formar uma espécie de papa não muito consistente. Rodrigues (2005) a chama de a mostarda da Amazônia. Sal, cebola, cheiro-verde, etc. podem ser adicionados ao
Tabela 1 - Produtos, formulações básicas e forma de uso de alguns produtos derivados de pimentas em Roraima.

\begin{tabular}{|c|c|c|c|}
\hline $\begin{array}{l}\text { क्ष } \\
\text { 홍 } \\
\text { 흔 }\end{array}$ & 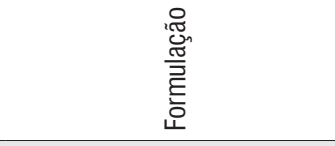 & 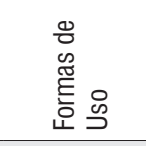 & 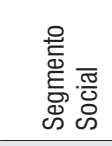 \\
\hline a. ARUBÉ & $\begin{array}{l}\text { Tucupi, goma, massa de } \\
\text { mandioca e pimenta (todos } \\
\text { cozidos juntos) }\end{array}$ & Condimento & Indígena \\
\hline b. CUMAXI & $\begin{array}{l}\text { Tucupi, pasta de pimentas } \\
\text { cozidas }\end{array}$ & Condimento & Indígena \\
\hline c. DAMORIDA & $\begin{array}{l}\text { Caldo de folhas e frutos de } \\
\text { pimenta }\end{array}$ & Alimento & Indígena \\
\hline d. JIQUITAIA & $\begin{array}{l}\text { Pimenta desidratada e moída } \\
\text { (pó) }\end{array}$ & Condimento & Indígena \\
\hline e. MOLHOS & $\begin{array}{l}\text { Pimentas inteiras e/ou } \\
\text { trituradas, acrescidas de uma } \\
\text { base líquida (tucupi, soro-de- } \\
\text { leite, óleo, água e sal,vinagre, } \\
\text { etc.) }\end{array}$ & Condimento & $\begin{array}{l}\text { Indígena / } \\
\text { não- } \\
\text { indígena }\end{array}$ \\
\hline $\begin{array}{l}\text { f. PIMENTAS } \\
\text { "IN NATURA" }\end{array}$ & Verdes, maduras, secas & $\begin{array}{l}\text { Condimento } \\
\text { e medicinal }\end{array}$ & $\begin{array}{l}\text { Indígena / } \\
\text { não- } \\
\text { indígena }\end{array}$ \\
\hline g. DOCE & $\begin{array}{l}\text { Pimenta "doce" moída, coco } \\
\text { ralado, açúcar }\end{array}$ & Sobremesa & $\begin{array}{l}\text { Não- } \\
\text { indígena }\end{array}$ \\
\hline h. LICOR & $\begin{array}{l}\text { Pimenta "doce" ou "de- } \\
\text { cheiro", aguardente e açúcar }\end{array}$ & Aperitivo & $\begin{array}{l}\text { Não- } \\
\text { indígena }\end{array}$ \\
\hline i. GELÉIA & $\begin{array}{l}\text { Pasta de pimentas com } \\
\text { açúcar }\end{array}$ & Alimento & $\begin{array}{l}\text { Não- } \\
\text { indígena }\end{array}$ \\
\hline
\end{tabular}

composto, mas com certeza, não retratam a formulação original. No passado, foi um preparado muito usado por várias etnias indígenas de Roraima (Macuxi, Taurepang, Ingaricó e Wapixana). É extremamente difícil de ser encontrado atualmente dentro das comunidades locais. Apenas aldeias mais distantes e isoladas, ou os indígenas mais idosos, ainda fazem deste alimento um hábito comum.

Cumaxi (kumasi) - Similar ao arubé. É usado pelos Macuxi e Taurepang, no Brasil, e também pelos Pemon na Venezuela. Segundo Pereira (1980), os Tupinambá também fazem um produto semelhante, e o chamam Tucupipichuna, que têm a mesma composição. Além da utilização como condimento, pode ser ingerido na porção de um cálice após as refeições como remédio para beribéri.

Damorida ou tamorida - É um caldo de folhas e frutos de pimentas de alta ardência (em geral malagueta), onde a carne de caça ou o peixe entram como complemento (proteína animal). É servido nas aldeias de todas as etnias do lavrado de Roraima. É comparado ao cafezinho para os não-étnicos, pois é servido em todas as ocasiões. É muito apreciado 
quando ingerido juntamente com o beiju. As famílias que tradicionalmente habitam o estado de Roraima (pioneiros) adotaram a damorida e, hoje, esse é um prato considerado tipicamente regional.

Jiquitaia - Também denominada juquitaia, inquitaia, juquirai. São pimentas desidratadas e moídas (piladas), às vezes, com sal, salpicando caças e peixes que são comumente assados. Cascudo (1968) apud Pereira (1980) evoca que os vocábulos salpimenta e salpimentar são nascidos funcionalmente da palavra indígena jiquitaia. Atualmente, diferentes comunidades locais (colonos) já se apropriaram dessa técnica de conservação das pimentas, vendendo este produto nas feiras de Roraima.

Molhos - É indiscutivelmente a técnica mais comum e popular de conservação e uso da pimenta em Roraima. A base líquida adotada por uma ampla gama de pequenos produtores rurais é calcada no tucupi da mandioca, óleo (principalmente o de soja), soro-de-leite do gado bovino, água e sal e vinagre. As comunidades indígenas dão preferência para molhos fabricados com o tucupi e, em um dos experimentos realizados em conjunto com a comunidade da Aldeia do Milho (Terra Indígena São Marcos) foi tentado o uso de uma base feita a partir de um escorrido da polpa de buriti.

Pimentas "in natura"-As diferentes formas de pimentas "in natura" (verdes, maduras, secas) são muito usadas por vários seguimentos sociais como condimentos (amassada diretamente na refeição) ou como medicinais, ornamentais, inseticidas e até como defumadoras de ambientes para afastar os maus espíritos. Algumas etnias locais usam espécies tradicionais dentro de ritos de passagem, como já mencionado no texto acima.

Doce, Licor e Geléia - São produtos de adaptações culturais externas que estão ocupando espaço (lentamente) no chamado "mercado de exóticos". Possuem pouca penetração entre as camadas da população de renda baixa. Vale ressaltar que as técnicas de confecção destes produtos ainda não são de amplo domínio pela maioria da população local, sendo seu uso pouco comum. Embora possa se utilizar pimentas com alto grau de ardência, os morfotipos mais indicados para estas três classes de produtos são as de baixo teor de ardência.

\section{CONCLUSÕES}

As formas de uso das pimentas, e seus derivados, observadas no que é hoje o estado de Roraima são muito variadas. A grande maioria é proveniente das culturas indígenas, sendo muito bem aceita pelas populações migrantes que já possuem o costume histórico de sua região de origem, ou se adaptam muito facilmente aos gostos e sabores das pimentas regionais. Outros produtos, derivados de centros de tradições diferentes, como geléias e doces, ainda não possuem um extenso conhecimento popular. Entretanto, possuem grande valor agregado superando os produtos tradicionais locais que investem na tecnologia familiar de produção. Embora haja distinções na forma de encarar alguns usos das pimentas pelos dois grandes segmentos sociais locais (indígenas e não-indígenas), ambos se aproveitam quase que exclusivamente destas plantas e de seus frutos para uso alimentar. Neste sentido, há uma base diferencial importante entre ambos os segmentos: enquanto que para os migrantes e seus descendentes a pimenta serve como um condimento (tempero) ao alimento diário, “... os indios de Roraima, encaram a pimenta não como tempero, mas como alimento ..." (Erwin H. Frank, Dep. de Antropolgia / UFRR, Comunicação Pessoal).

\section{BIBLIOGRAFIA CITADA}

Azevedo Lima, R.R.O. 1990. Levantamentos preliminares sobre as roças Waimi-Atroari. (relatório não-publicado). Manaus, Programa Waimiri-Atroari/Convênio FUNAI-ELETRONORTE. 7pp.

Barbosa, R.I.; Miranda, I.S. 2005. Fitofisionomias e diversidade vegetal das savanas de Roraima. In: Barbosa, R.I.; Xaud, H.A.M.; Costa e Souza, J.M. (orgs.), Savanas de Roraima: Etnoecologia, Biodiversidade e Potencialidades Agrossilvipastoris. Boa Vista, FEMACT. p. 61-78.

Barbosa, R.I.; Luz, F..J..F.; Nascimento Filho, H.R.; Maduro, C.B. 2002. Pimentas do gênero Capsicum cultivadas em Roraima, Amazônia brasileira. I. Espécies Domesticadas. Acta Amazonica, 32(2): 177-192.

Barbosa, R.I.; Luz, F..J..F.; Nascimento Filho, H.R.; Maduro, C.B. 2006. Pimentas de Roraima (Catálogo de Referência). Manaus, INPA/EDUA. 93pp.

Berg, E.M.V.D.; Silva, M.H.L. 1988. Contribuição ao conhecimento da flora medicinal de Roraima. Acta Amazonica, 18(1/2):2335.

Casali, V.W.D.; Couto, F.A.A. 1984. Origem e botânica de Capsicum. Informe Agropecuário (Belo Horizonte), 10(113): 8-10.

Garcia, A.J.V. 1991. El aji (Capsicum chinense Jacq.) - Patrimônio cultural y filogenético de las culturas Amazonicas. Colombia Amazonica, 5(1):161-185.

Heiser, C.B.; Smith, P.G. 1953. The cultivated Capsicum peppers. Economic Botany, (7):214-227.

Heiser, C.B. 1976. Peppers: Capsicum (Solanaceae). In: Simmonds, N.W. (ed.), Evolution of Crop Plants. Londres, Longman. p. 265-268.

Koch-Grünberg, T. 1979-82. Del Roraima al Orinoco. (Tomo I, II e III). Caracas, Ediciones del Banco Central de Venezuela.

Lorimer, J. 1989. English and Irish settlement on the River Amazon, 1550-1646. Londres, The Hakluyt Society. p. 103-108.

Meggers, B. J. 1987. Amazônia: a ilusão do paraíso. São Paulo, EDUSP. 239pp.

Mentz Ribeiro, P.A. 1997. Arqueologia em Roraima: histórico e evidências de um passado distante. In: Barbosa, R.I. ; Ferreira, E.J.G.; Castellón, E.G. (eds.), Homem, Ambiente e Ecologia no Estado de Roraima. Manaus, INPA. pp 3-23. 


\section{ACTA}

Milliken,W. 1997. Traditional anti-malarial medicine in Roraima, Brazil. Economic Botany, 51(3): 212-237.

Milliken, W.; Albert, B. 1997. The use of medicinal plants by the Yanomami Indians of Brazil, Part II. Economic Botany, 51(3): 264-278.

Milliken, W.; Miller, R.P.; Pollard, S.R.; Wanderlli, E.V. 1992. Ethnobotany of the Waimiri-Atroari Indians of Brazil. Kew/ Londres, Royal Botanic Gardens. 146pp.

Milliken, W.; Albert, B.; Goodwin Gomez, G. 1999. Yanomami: a forest people. Kew/Londres, Royal Botanic Gardens. 161pp.

Nuez, F.; Diez, M.J.; Ruiz, J.J.; Cordova, P.F.; Costa, J.; Catalá, M.S.; González, J.A.; Rodríguez, A. 1998. Catálogo de semilias de pimiento. Madri, Ministerio de Agricultura, Pesca y Alimentación / Instituto Nacional de investigación y Tecnologia Agraria y Alimentaria. 108pp.

Papavero, N.; Teixeira, D.M.; Overal, W.L. ; Pujol-Luz, J.R. 2000. O Novo Éden: a fauna da Amazônia brasileira nos relatos de viajantes e cronistas desde a descoberta do rio Amazonas por Pinzón (1500) até o Tratado de Santo Idelfonso (1777). Belém, Museu Paraense Emílio Goeldi. 328pp.
Pereira, N. 1980. Moronguêtá: um decameron indígena (vol. I). Rio de Janeiro, Civilização Brasileira (1 a edição, 1967). 434pp.

Reifschneider, F.J.B. 2000. Capsicum: pimentas e pimentôes no Brasil. Brasília, EMBRAPA (Hortaliças).113pp.

Rodrigues, A.B. 2005. Arubé. Revista Nosso Pará. Disponível em: http://www.revistanossopara.com.br/conteudo. php? edicao=7\&indice=54. Acesso em fevereiro de 2005 .

Staden, H. 1974. Duas viagens ao Brasil. São Paulo, EDUSP. 206pp.

Ule, E. 1913. (14) Hr. E. Ule hält den angekündigten Vortrag: unter den Indianern am Rio Branco in Nordbrasilien. In: Zeitschrift für Ethnologie, Jhrg. 45, Heft 2, Berlim. p. 278-298.

Recebido em 25/04/2006

Aceito em 15/08/2007 
